\title{
Sodium supply influences plasma sodium concentration and the risks of hyper- and hyponatremia in extremely preterm infants
}

\author{
Cornelia Späth', Elisabeth Stoltz Sjöström², Fredrik Ahlsson³ ${ }^{3}$ Johan Ågren ${ }^{3}$ and Magnus Domellöf'
}

BACKGROUND: Hyper- and hyponatremia occur frequently in extremely preterm infants. Our purpose was to investigate plasma sodium ( $\mathrm{P}-\mathrm{Na}$ ) concentrations, the incidence of hyperand hyponatremia, and the impact of possible predisposing factors in extremely preterm infants.

METHODS: In this observational study, we analyzed data from the EXtremely PREterm ( $<27$ wk.) infants in Sweden Study (EXPRESS, $n=707$ ). Detailed nutritional, laboratory, and weight data were collected retrospectively from patient records.

RESULTS: Mean \pm SD P-Na increased from $135.5 \pm 3.0$ at birth to $144.3 \pm 6.1 \mathrm{mmol} / \mathrm{l}$ at a postnatal age of $3 \mathrm{~d}$ and decreased thereafter. Fifty percent of infants had hypernatremia (P-Na > $145 \mathrm{mmol} / \mathrm{l}$ ) during the first week of life while 79\% displayed hyponatremia (P-Na $<135 \mathrm{mmol} / \mathrm{l})$ during week 2. Initially, the main sodium sources were blood products and saline injections/infusions, gradually shifting to parenteral and enteral nutrition towards the end of the first week. The major determinant of P-Na and the risks of hyper- and hyponatremia was sodium supply. Fluid volume provision was associated with postnatal weight change but not with P-Na.

CONCLUSION: The supply of sodium, rather than fluid volume, is the major factor determining P-Na concentrations and the risks of hyper-and hyponatremia.

\footnotetext{
$\mathbf{S}_{\mathrm{n}}$
} dium, the major cation in the extracellular fluid determines extracellular fluid volume, impacts on blood pressure and is essential for growth and central nervous system function $(1,2)$. At birth, the reduction in extracellular fluid is considered a part of the adaptation of cardiorespiratory function (3). In extremely preterm (EPT) infants, higher body water content together with large insensible water losses increases the risk of hypernatremia early after birth. On the other hand, the same infants a few days later will typically develop hyponatremia due to immature renal function with high urinary sodium losses. Hypernatremia (plasma sodium (P-Na) 145 $\mathrm{mmol} / \mathrm{l}$ ) has been reported in $70 \%$ of infants below $27 \mathrm{wk}$ of gestation, most frequently occurring at 24-72 $\mathrm{h}$ after birth (4). From the second week of life, hyponatremia is almost universal in EPT infants, unless sodium is supplemented. Perturbations in sodium and water metabolism are clinically relevant: Hypernatremia, high sodium supply as well as high fluctuation of serum sodium may increase the risk of cerebral hemorrhage (4-7) while hyponatremia may cause cerebral edema and encephalopathy (8). Accordingly, large changes in serum sodium concentrations have been associated with adverse neurological outcome (9) and preterm infants supplemented with sodium starting at a postnatal age (PNA) of 4-7 d displayed less hyponatremia $(10,11)$ and better neurodevelopmental outcome compared with controls (12). The knowledge about how fluid and electrolyte management interacts with the postnatal changes in extracellular fluid is limited. Specifically, it is unclear to what extent sodium concentration is affected by sodium supply and fluid volume, respectively, and whether one of them might be the major conveyor of the observed unwanted effects on brain health. We aimed to investigate the course of P-Na concentrations, the incidence of hyper- and hyponatremia, and their possible association with predisposing factors in EPT infants.

\section{METHODS}

\section{Study Population}

We used prospective data form the population-based Extremely Preterm Infants in Sweden Study (EXPRESS). The EXPRESS cohort consist of infants born at $<27 \mathrm{wk}$ of gestation in Sweden during a 3-y period $(n=707)(13,14)$. Nutritional intakes and postnatal growth of EXPRESS infants, surviving the first $24 \mathrm{~h}$ after birth, have recently been reported $(15,16)$.

\section{Data Collection}

All data, including enteral and parenteral fluids, flush solutions containing sodium, and blood products were retrospectively collected daily from hospital records from the day of birth (PNA of $0 \mathrm{~d}$ ) to a PNA of $14 \mathrm{~d}$. Nutritional intakes were calculated from manufacturer information and published nutrient contents (17-19). Sodium supply and fluid volume at the day of birth were corrected for time of birth. Furthermore, all weight measurements and the first available plasma or serum sodium concentration each day were obtained. Since the vast majority of sodium analyses were performed on plasma samples using different point-of-care blood gas analyzers (most common system: Radiometer, Åkandevej 21, 2700 Brønshøj, Denmark), sodium values are reported as $\mathrm{P}-\mathrm{Na}$ concentrations. There is a high level of

'Department of Clinical Sciences, Pediatrics, Umeå University, Umeå, Sweden; '2Department of Food and Nutrition, Umeå University, Umeå, Sweden; ${ }^{3}$ Department of Women's and Children's Health, Uppsala University, Uppsala, Sweden. Correspondence: Magnus Domellöf (magnus.domellof@umu.se)

Received 16 August 2016; accepted 9 October 2016; advance online publication 18 January 2017. doi:10.1038/pr.2016.264 
agreement between the results obtained from blood gas (Radiometer) and laboratory analyzers (20).

\section{Data Management}

Presently, there are no universally agreed definitions of hyperand/or hyponatremia. In this study, we defined hypernatremia as $\mathrm{P}-\mathrm{Na}>145 \mathrm{mmol} / \mathrm{l}$, mild hypernatremia as $\mathrm{P}-\mathrm{Na}$ between 146 and $150 \mathrm{mmol} / \mathrm{l}$, moderate hypernatremia as $\mathrm{P}-\mathrm{Na}$ between 151 and $155 \mathrm{mmol} / \mathrm{l}$, and severe hypernatremia as $\mathrm{P}-\mathrm{Na}>155 \mathrm{mmol} / \mathrm{l}$. Hyponatremia was defined as $\mathrm{P}-\mathrm{Na}<135 \mathrm{mmol} / \mathrm{l}$, mild hyponatremia as P-Na between 130 and $134 \mathrm{mmol} / \mathrm{l}$, moderate hyponatremia as P-Na between 125 and $129 \mathrm{mmol} / \mathrm{l}$, and severe hyponatremia as $\mathrm{P}-\mathrm{Na}<125 \mathrm{mmol} / \mathrm{l}$. Infants who died within the first $24 \mathrm{~h}$ after birth ( $n=105)$ were excluded from all analyses due to lack of available nutritional intake data. Infants with multiple congenital anomalies $(n=3)$, gastrointestinal malformation $(n=2)$, limb reduction defects $(n=2)$, and chromosomal anomalies $(n=3)$ were excluded from all analyses due to possible interaction with metabolism, nutrition status and/or weight.

Weight measurements were available on an average of $3.2 \mathrm{~d}$ during the first week of life (PNA of 0-6 d). For days with missing weight data, weight change from birth (percent weight change) was calculated by linear interpolation. When weight measurements were missing on 4 or more consecutive days, data was not interpolated. Prospective perinatal data were collected within the EXPRESS cohort and included gestational age (GA), birth weight (BW), Apgar scores, clinical risk index for babies (CRIB), antenatal steroids and days on mechanical ventilation (MV) $(13,14)$.

\section{Statistical Analyses}

SPSS Statistical software (Version 23.0 for Windows, SPSS, Chicago, IL) was used. Since the proportion of fluid volume was strongly correlated with sodium supply $(r=+0.80, P<0.001)$ the standardized residuals of the regression of fluid volume on sodium supply were calculated and used as a measure of fluid volume except when testing the outcome percent weight change. Apgar scores, CRIB and MV (days during first week of life) were treated as continuous variables.

Univariable linear regression analyses were performed for the outcomes $\mathrm{P}-\mathrm{Na}$ and percent weight change. Univariable logistic regression analyses were performed for the outcomes hyper- and hyponatremia, except when testing the binary explanatory factors small for gestational age, antenatal steroids and MV during a PNA of 0-3 d (solely hypernatremia analyses), for which independent samples $t$-tests were performed. $P$-values $<0.05$ were considered significant.

For hypernatremia and P-Na at a PNA of 2-4 d, possible explanatory variables tested were: Sodium supply, provided fluid volume, percent weight change, GA, BW, BW standard deviation scores (SDS), small for gestational age, Apgar scores, CRIB, antenatal steroids and MV during a PNA of $0-3 \mathrm{~d}$. For hyponatremia and P-Na at a PNA of $10 \mathrm{~d}$, the same explanatory variables were tested, with the exception of percent weight change and Apgar scores. MV during a PNA of 0-3 d was replaced by MV during the first week of life.

Finally, we performed multivariable linear and logistic regression analyses including all variables that were significant in the corresponding univariable analyses.

For analyses of differences in hyper- and hyponatremia between hospitals independent sample $t$-test was used for continuous variables and Fisher's exact probability test for binary variables. Values are mean \pm SD and (range), unless otherwise noted.

\section{Ethics}

The EXPRESS study was approved by the Regional Ethical Review Board in Lund, Sweden (Dnr 138-2008). The ethical committee declared waiver of consent for this additional study.

\section{RESULTS}

The analyses are based on a final cohort of 592 infants. The mean \pm SD (range) GA and BW of infants were $25.3 \pm 1.1 \mathrm{wk}$ $(22.1-26.9)$ and $765 \pm 169$ grams $(348-1,315)$. Figure 1 illustrates P-Na concentrations during the first $28 \mathrm{~d}$ after birth.

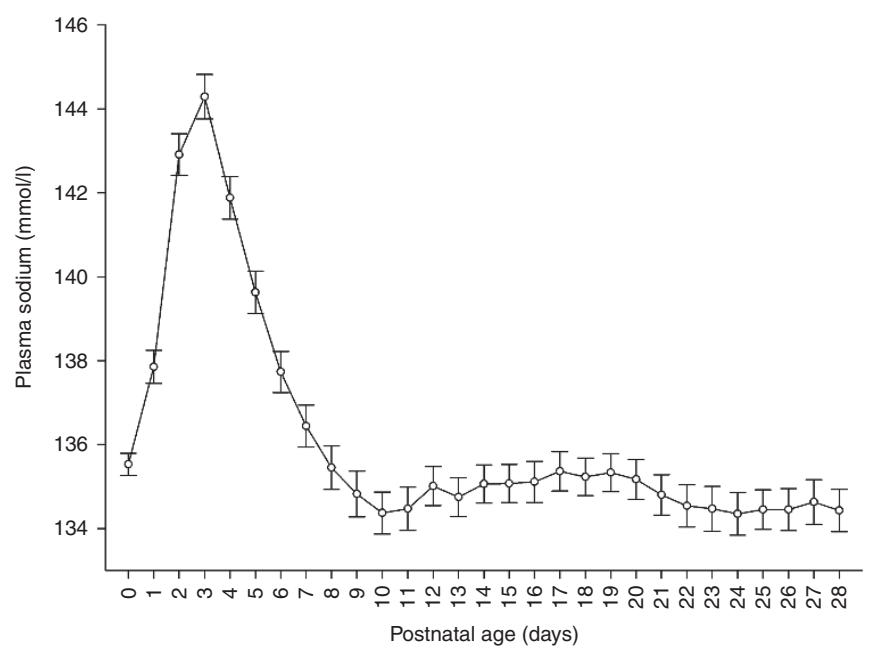

Figure 1. Plasma sodium concentrations of extremely preterm infants during the first $28 \mathrm{~d}$ after birth ( $95 \%$ confidence interval for mean). The number of infants included each day varies between 265 and 547.

\section{Sodium Supply}

The sources of sodium and their relative contribution to total sodium supply are shown in Figure 2. Sodium sources at a PNA of 0-3 d were mainly blood products and saline injections/infusions. At a PNA of 4-6 d parenteral nutrition was the main sodium source, while during days 7-13 after birth infants received sodium mainly through enteral and parenteral nutrition.

\section{Incidences of Hyper- and Hyponatremia}

During the first week of life, 282/556 infants (50\%) had hypernatremia (whereof 29\% mild, 16\% moderate, and 5\% severe), appearing most frequently at days 2-4 after birth (Figure 3). Of 515 infants, 404 (79\%) had hyponatremia (whereof 39\% mild, 32\% moderate and $8 \%$ severe) during the second week of life (PNA of 7-13 d), appearing most frequently around day 10 after birth. From a PNA of $5 \mathrm{~d}$ more infants displayed hyponatremia compared with hypernatremia.

\section{Weight Change}

Postnatal weight change was $-10 \pm 7 \%(-31 \%$ to $+13 \% ; n=347)$ with a nadir at a PNA of $4 \mathrm{~d}$ whereby 98 infants (28\%) had lost between 5 and $10 \%$ of their birth weight and 182 infants (53\%) had lost more than $10 \%$ of their birth weight. Average daily fluid volume provision during days $0-3$ after birth was significantly associated with percent weight change from birth to $4 \mathrm{~d}$ of life $(r=+0.482, P<0.001)$. When percent weight change from birth was calculated with available daily measured weight data (no linear interpolation) these association remained.

\section{Hypernatremia}

Factors associated with P-Na at a PNA of 2-4 d, are shown in Supplementary Table S1 online (univariable analyses) and Table 1 (multivariable analyses). Factors associated with the occurrence of hypernatremia at a PNA of 2, 3, and $4 \mathrm{~d}$ are shown in Supplementary Table S2 online (univariable analyses) and 
Table 2 (multivariable analyses). In addition, univariable analyses showed that P-Na at day 4 after birth was significantly correlated with administration of antenatal steroids $(P=0.001)$. In multivariable analyses, the major determinant of $\mathrm{P}-\mathrm{Na}$ and hypernatremia was sodium supply during the preceding days. Factors associated with moderate/severe hypernatremia (P-Na $>150 \mathrm{mmol} / \mathrm{l}$ ) were similar (data not shown).

When we additionally excluded infants who died during the first week of life and/or infants with incomplete laboratory and/or nutritional data ( $<4$ values during week 1$)$ from the analyses of hypernatremia the results remained.

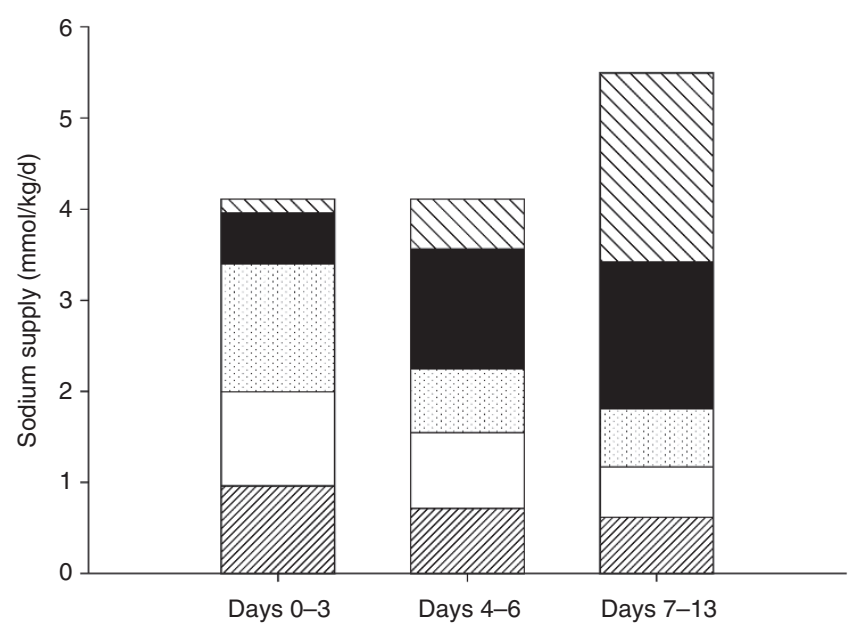

Figure 2. Sources of sodium supply of extremely preterm infants during a postnatal age (PNA) of 0-3 d ( $n=576)$, a PNA of $4-6 \mathrm{~d}(n=549)$, and a PNA of 7-13 d ( $n=539)$. 27 Saline infusions; $\square$ saline-flush injections; $\because \cdot$ blood products; $\quad$ parenteral nutrition; $\mathbf{W}$ and enteral nutrition.

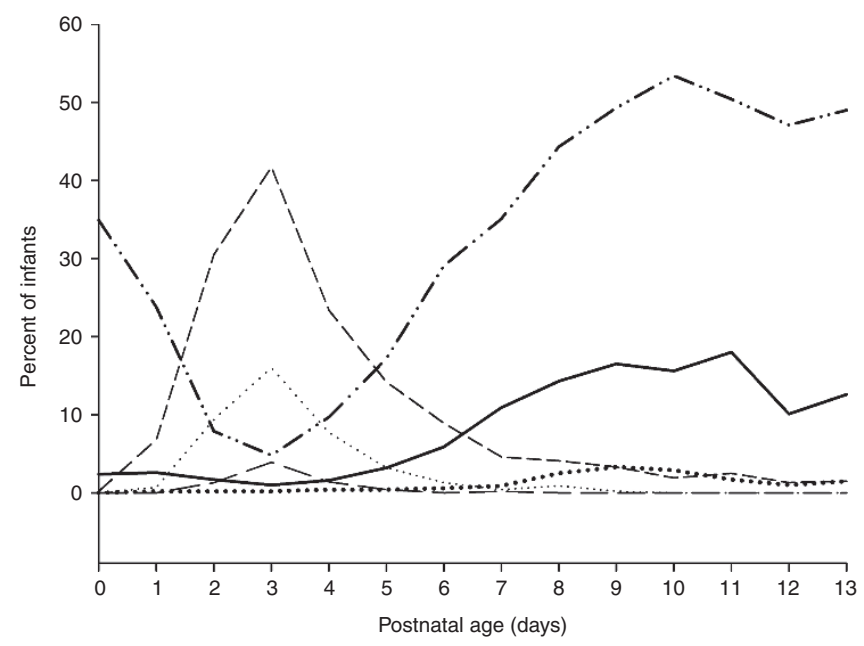

Figure 3. Daily occurrence of hyper- and hyponatremia during the first $2 \mathrm{wk}$ of life in extremely preterm infants. The number of infants included each day varies between 392 and 547.--- Hypernatremia (P-Na > 145 $\mathrm{mmol} / \mathrm{l}) ;$......... Moderate/severe hypernatremia (P-Na > $150 \mathrm{mmol} / \mathrm{l}$; _- Severe hypernatremia (P-Na $>155 \mathrm{mmol} / \mathrm{l}) ;-$ - Hyponatremia (P-Na $<135 \mathrm{mmol} / \mathrm{l}) ;$ Moderate/severe hyponatremia $(\mathrm{P}-\mathrm{Na}<130 \mathrm{mmol} / \mathrm{l})$; ..... Severe hyponatremia ( $\mathrm{P}-\mathrm{Na}<125 \mathrm{mmol} / \mathrm{l})$.
Routines for sodium supply varied between Sweden's six university hospitals, making it possible for us to compare $\mathrm{P}-\mathrm{Na}$ in infants treated at the two hospitals with the most liberal sodium supply with infants at the hospital with the most restrictive sodium supply. In agreement with the above findings, the occurrence of hypernatremia at a PNA of 2, 3, and $4 \mathrm{~d}$ was significantly higher $(32-50 \%$ vs. $8-28 \%, P=0.001$, $P<0.001$, respectively) in hospitals where the infants received most sodium compared with infants at the hospital with the lowest sodium supply $(5.5 \pm 2.5 \mathrm{mmol} / \mathrm{kg} / \mathrm{d}$ vs. $1.3 \pm 1.0 \mathrm{mmol} /$ $\mathrm{kg} / \mathrm{d}$ on average at days $0-3$ after birth; $n=162$ vs. $n=114$ ). There was no significant difference in infant GA between these hospitals $(P=0.437)$.

\section{Hyponatremia}

Factors associated with P-Na at a PNA of $10 \mathrm{~d}$, are shown in Supplementary Table S1 online (univariable analyses) and Table 1 (multivariable analyses). In final multivariable analyses sodium supply during the preceding days (days 4-9 after birth) was the only factor significantly correlating with $\mathrm{P}-\mathrm{Na}$ at a PNA of $10 \mathrm{~d}$. In accordance with that, final multivariable analyses showed that low sodium supply at days 4-9 after birth was the only remaining factor associated with hyponatremia at a PNA of $10 \mathrm{~d}$ (odds ratio, $\mathrm{OR}=0.85(0.77-0.93), P<0.001$ ). Fluid volume had neither effect on P-Na nor on the occurrence of hyponatremia at a PNA of $10 \mathrm{~d}$. Results for moderate/ severe hyponatremia $(\mathrm{P}-\mathrm{Na}<130 \mathrm{mmol} / \mathrm{l})$ were similar (data not shown).

When additionally excluding infants who died within the first 2 wk of life (days $0-13$ ) and/or infants with incomplete laboratory and/or nutritional data from the analyses of hyponatremia the results remained.

The occurrence of hyponatremia at a PNA of $10 \mathrm{~d}$ was significantly lower ( $49 \%$ vs. $71 \%, P=0.001)$ among infants at the hospitals with the highest average daily sodium supply compared with infants at the hospital with the lowest average daily sodium supply during days $4-9$ after birth $(5.8 \pm 2.1 \mathrm{mmol} /$ $\mathrm{kg} / \mathrm{d}$ vs. $2.8 \pm 1.8 \mathrm{mmol} / \mathrm{kg} / \mathrm{d} ; n=158$ vs. $n=111)$.

\section{DISCUSSION}

We present data on fluid and sodium homeostasis in a population based, homogenous, and very well described cohort of EPT infants. The most important finding of this study is that the provision of sodium itself is the major factor determining $\mathrm{P}-\mathrm{Na}$ concentrations as well as the risks of hyper- and hyponatremia. Provided fluid volume, while influencing weight loss, had no impact on P-Na concentrations as well as the occurrence of hyponatremia and only a minor impact on the occurrence of hypernatremia at a PNA of $4 \mathrm{~d}$.

In this study more than $20 \%$ of infants had P-Na $>150$ $\mathrm{mmol} / \mathrm{l}$ during the first week of life, and $40 \%$ had P-Na $<130$ $\mathrm{mmol} / \mathrm{l}$ during the second week of life. Average P-Na peaked at a PNA of $3 \mathrm{~d}$ and decreased thereafter to a lowest concentration on day 10 after birth. After a PNA of $7 \mathrm{~d}$, no infant had severe hypernatremia (P-Na $>155 \mathrm{mmol} / \mathrm{l})$. In parallel, 
Table 1. Factors associated with plasma sodium (P-Na) concentrations in extremely preterm infants

\begin{tabular}{|c|c|c|c|c|}
\hline & $\begin{array}{c}\text { P-Na (mmol/l) Day } 2 \\
(n=337)\end{array}$ & $\begin{array}{c}\text { P-Na (mmol/l) Day } 3 \\
(n=514)\end{array}$ & $\begin{array}{c}\text { P-Na (mmol/I) Day } 4 \\
(n=501)\end{array}$ & $\begin{array}{l}\text { P-Na }(\mathrm{mmol} / \mathrm{l}) \\
\text { Day } 10(n= \\
413)\end{array}$ \\
\hline Na supply $(\mathrm{mmol} / \mathrm{kg} / \mathrm{d})^{\mathrm{a}}$ & $+0.335^{*}$ & $+0.292^{*}$ & $+0.345^{*}$ & $+0.261^{*}$ \\
\hline Gestational age (wk) & $-0.221^{*}$ & $-0.178^{*}$ & NS & - \\
\hline Percent weight change ${ }^{b}$ & $-0.186^{*}$ & - & - & - \\
\hline 5-min Apgar & NS & NS & $-0.115^{* *}$ & - \\
\hline Antenatal steroids (any) & - & - & $+0.137^{* *}$ & - \\
\hline R-square for model & 0.199 & 0.135 & 0.157 & 0.068 \\
\hline
\end{tabular}

NS, nonsignificant; -, Factors not taken into account in the respective analyses due to nonsignificant univariable associations with P-Na concentration or due to insufficient theoretical background.

${ }^{a}$ Average daily sodium supply from enteral and parenteral fluids at the preceding days (days $0-1,0-2,0-3$, and $4-9$ ). ${ }^{\text {b }}$ Until a postnatal age of 2 d. ${ }^{*} P<0.001$, ${ }^{* *} P<0.01$. Multivariable linear regression analysis.

Solely factors significantly associated with P-Na concentration in one of the multivariable analyses are taken into account.

Table 2. Factors associated with hypernatremia in extremely preterm infants

\begin{tabular}{|c|c|c|c|}
\hline & $\begin{array}{l}\text { Hypernatremia Day } 2^{\mathrm{a}} \\
\qquad(n=337)\end{array}$ & $\begin{array}{l}\text { Hypernatremia Day } 3^{a} \\
(n=514)\end{array}$ & $\begin{array}{l}\text { Hypernatremia Day } 4^{\mathrm{a}} \\
\qquad(n=501)\end{array}$ \\
\hline & OR & OR & OR \\
\hline Na supply days $0-1(\mathrm{mmol} / \mathrm{kg} / \mathrm{d})^{\mathrm{b}}$ & $1.31 *$ & - & - \\
\hline Na supply days $0-2(\mathrm{mmol} / \mathrm{kg} / \mathrm{d})^{\mathrm{b}}$ & - & $1.16^{*}$ & - \\
\hline Na supply days $0-3(\mathrm{mmol} / \mathrm{kg} / \mathrm{d})^{\mathrm{b}}$ & - & - & $1.33^{*}$ \\
\hline Fluid volume days $0-3(\mathrm{ml} / \mathrm{kg} / \mathrm{d})^{\mathrm{c}}$ & - & - & $0.74^{* *}$ \\
\hline Gestational age (wk) & $0.48^{*}$ & $0.69^{*}$ & NS \\
\hline Percent weight change $^{d}$ & $0.92^{* *}$ & - & - \\
\hline
\end{tabular}

NS, nonsignificant; OR, odds ratio; -, Factors not taken into account in the respective analyses due to nonsignificant univariable associations with hypernatremia or due to nonconforming time interval of sodium or fluid intake.

a Plasma sodium > $145 \mathrm{mmol} / /$ occurring at a postnatal age of 2, 3 respectively $4 \mathrm{~d} .{ }^{\text {b }}$ Average daily sodium supply from enteral and parenteral fluids. ${ }^{c}$ Average daily fluid volume corrected for sodium from enteral and parenteral fluids. ${ }^{\mathrm{d}}$ Until a postnatal age of $2 \mathrm{~d}$.

${ }^{*} P<0.001,{ }^{* *} P<0.01$. Multivariable logistic regression analyses.

Solely factors significantly associated with hypernatremia in one of the multivariable analyses are taken into account.

the occurrence of hyponatremia was lowest at a PNA of $3 \mathrm{~d}$ and then increased until day 10 after birth.

In final multivariable models, sodium supply was the strongest predictor of $\mathrm{P}-\mathrm{Na}$ and the risk of hyper- and hyponatremia. The results were further confirmed by exploring differences in clinical management: In hospitals where sodium was given most liberally, infants were at higher risk of hypernatremia as well as at lower risk of hyponatremia compared with hospitals with the lowest sodium provision.

One might have expected to find strong associations between low fluid volume and high P-Na and/or between high fluid volume and low P-Na. However, fluid provision was not at all related to $\mathrm{P}-\mathrm{Na}$ as well as hyponatremia, and not consistently with hypernatremia. We found a negative association between provided fluid volume and hypernatremia at a PNA of $4 \mathrm{~d}$. Furthermore, postnatal weight change, a proxy for fluid volume provision, was significantly negative correlated with $\mathrm{P}-\mathrm{Na}$ as well as hypernatremia at day 2 after birth, implying a weak association between low fluid volume and hypernatremia whereas the provision of sodium was continuously and strongly correlated with $\mathrm{P}-\mathrm{Na}$ concentration and the risk of hypernatremia.
P-Na concentration was also associated with administration of antenatal steroids, which have been shown to decrease the incidence of hypernatremia, presumably through its maturational effect on both skin barrier and renal tubular function (21). In contrast, we found a weak effect in the opposite direction. However, this was only found at one of the investigated time points and few infants in our cohort had not received antenatal steroids so this result may be a chance finding.

Similar to at least one other study in preterm infants (22), we found that many infants (one third) displayed hyponatremia $(\mathrm{P}-\mathrm{Na}<135 \mathrm{mmol} / \mathrm{l})$ already in the first analyzed sample at a PNA of $0 \mathrm{~d}$. The relevance of this finding is unclear but might be related to the rapid redistribution and loss of body water that takes place at birth $(23,24)$.

Kavvadia et al. compared a restricted vs. a liberal fluid regimen in extremely low birth weight infants and found no differences in hyper- or hyponatremia, short-term morbidity or mortality between the groups (25). Sodium supply was similar in the two groups (26). The fluid restricted infants had a lower urinary output and a higher urinary osmolality than those receiving standard fluid volumes, suggesting that even extremely low birth weight infants are able to regulate fluid 
balance in response to variations in fluid volume provision. In contrast, a similar study, with a higher sodium supply in the liberal fluid group, suggested that a high sodium supply carries an increased risk of both mortality and respiratory morbidity (27). Costarino et al. compared a higher vs. a lower sodium supply during the first 3-5 d after birth and showed a significantly lower incidence of bronchopulmonary dysplasia in the sodium-restricted infants (28). When comparing early vs. delayed sodium supplementation, positive effects on oxygen regulation have been shown when sodium supplementation begins after weight loss has taken place (29). Several studies suggest that preterm infants benefit from sodium supplementation started after a few days by decreased risk of hyponatremia, improved weight gain, earlier discharge and possibly even improved neurodevelopmental outcomes (10-12).

Our results support previous research suggesting that sodium supply should be minimized until day 3 after birth and it is important to realize that non-nutritional sodium sources (blood transfusions, plasma transfusions, saline flushes, and saline infusions) should be taken into account since they contribute most of the sodium during this period. However, from a PNA of $4 \mathrm{~d}$, an adequate sodium supply should be ensured to minimize the risk of hyponatremia.

During the second week of life average daily sodium supply was $5.5 \mathrm{mmol} / \mathrm{kg} / \mathrm{d}$. This high sodium supply in combination with the high incidence of hyponatremia may suggest that the recommended daily sodium supply of $3-5 \mathrm{mmol} / \mathrm{kg} / \mathrm{d}$ during the phase of stable growth may be to low (30).

Strengths of this study include a relatively large, population based sample and extensive data acquisition. Limitations of this study are the observational design and retrospective data collection. Also, this study did not include data on urinary and insensible water losses. However, all infants were treated in closed and highly humidified incubators.

To conclude, a majority of EPT infants in Sweden had hyperand/or hyponatremia. The provision of sodium is the main factor determining P-Na concentrations as well as the risks of hyper- and hyponatremia. Fluid volume has a minor impact on the occurrence of hypernatremia.

\section{SUPPLEMENTARY MATERIAL}

Supplementary material is linked to the online version of the paper at http:// www.nature.com/pr

\section{ACKNOWLEDGMENTS}

We thank Ann-Cathrine Berg, Cecilia Ewald, Anne Rosenkvist, Caroline Törnqvist, and Vera Westin for entering and checking data.

\section{STATEMENT OF FINANCIAL SUPPORT}

Funding sources: A regional agreement between Umeå University and Västerbotten County Council in co-operation in the field of Medicine, Odontology and Health (ALF).

Disclosure: Neither of the authors has a conflict of interest to disclose.

\section{REFERENCES}

1. Marcialis MA, Dessi A, Pintus MC, Marinelli V, Fanos V. Hyponatremia and hypernatremia in the newborn: in medio stat virtus. Front Biosci (Elite Ed). 2012;4:132-40.

2. Haycock GB. The influence of sodium on growth in infancy. Pediatr Nephrol 1993;7:871-5.
3. Fusch C, Jochum F. Water, sodium, potassium and chloride. In: Koletzko B, Poindexter B, Uauy R, eds. Nutritional Care of Preterm Infants. Scientific Basis and Practical Guidelines. Basel, Switzerland: Karger AG, 2014: 99-120.

4. Gawlowski Z, Aladangady N, Coen PG. Hypernatraemia in preterm infants born at less than 27 weeks gestation. J Pediatr Child Health 2006;42:771-4.

5. Lim WH, Lien R, Chiang MC, et al. Hypernatremia and grade III/IV intraventricular hemorrhage among extremely low birth weight infants. J Perinatol 2011;31:193-8.

6. Barnette AR, Myers BJ, Berg CS, Inder TE. Sodium intake and intraventricular hemorrhage in the preterm infant. Ann Neurol 2010;67:817-23.

7. Lee HJ, Lee BS, Do HJ, et al. Early sodium and fluid intake and severe intraventricular hemorrhage in extremely low birth weight infants. J Korean Med Sci 2015;30:283-9.

8. Moritz ML, Ayus JC. Disorders of water metabolism in children: hyponatremia and hypernatremia. Pediatr Rev 2002;23:371-80.

9. Baraton L, Ancel PY, Flamant C, Orsonneau JL, Darmaun D, Rozé JC. Impact of changes in serum sodium levels on 2-year neurologic outcomes for very preterm neonates. Pediatrics 2009;124:e655-61.

10. Al-Dahhan J, Haycock GB, Nichol B, Chantler C, Stimmler L. Sodium homeostasis in term and preterm neonates. III. Effect of salt supplementation. Arch Dis Child 1984;59:945-50.

11. Isemann B, Mueller EW, Narendran V, Akinbi H. Impact of early sodium supplementation on hyponatremia and growth in premature infants: a randomized controlled trial. JPEN J Parenter Enteral Nutr 2016;40:342-9.

12. Al-Dahhan J, Jannoun L, Haycock GB. Effect of salt supplementation of newborn premature infants on neurodevelopmental outcome at 10-13 years of age. Arch Dis Child Fetal Neonatal Ed 2002;86:F120-3.

13. The EXPRESS Group. One-year survival of extremely preterm infants after active perinatal care in Sweden. JAMA 2009;301:2225-33.

14. The EXPRESS Group. Incidence of and risk factors for neonatal morbidity after active perinatal care: extremely preterm infants study in Sweden (EXPRESS). Acta Pediatr 2010;99:978-92.

15. Stoltz Sjöström E, Öhlund I, Ahlsson F, et al. Nutrient intakes independently affect growth in extremely preterm infants: results from a population-based study. Acta Pediatr 2013;102:1067-74.

16. Sjöström ES, Öhlund I, Ahlsson F, Domellöf M. Intakes of micronutrients are associated with early growth in extremely preterm infants. J Pediatr Gastroenterol Nutr 2016;62:885-92.

17. Rossi E, Simon T, Moss G, Gould S. Principles of Transfusion Medicine. 2nd ed. Baltimore: Williams \& Wilkins, 1996.

18. Wadsworth GR, Oliveiro CJ. Plasma protein concentration of normal adults living in Singapore. Br Med J 1953;2:1138-9.

19. Fomon SJ. Nutrition of Normal Infants. Philadelphia: WB Saunders, 1993.

20. Mirzazadeh M, Morovat A, James T, Smith I, Kirby J, Shine B. Point-of-care testing of electrolytes and calcium using blood gas analyzers: it is time we trusted the results. Emerg Med J 2016;33:181-6.

21. Omar SA, DeCristofaro JD, Agarwal BI, La Gamma EF. Effects of prenatal steroids on water and sodium homeostasis in extremely low birth weight neonates. Pediatrics 1999;104(3 Pt 1):482-8.

22. Rees L, Brook CG, Shaw JC, Forsling ML. Hyponatremia in the first week of life in preterm infants. Part I. Arginine vasopressin secretion. Arch Dis Child 1984;59:414-22.

23. Modi N. Development of renal function. Br Med Bull 1988;44:935-56.

24. Lorenz JM, Kleinman LI, Ahmed G, Markarian K. Phases of fluid and electrolyte homeostasis in the extremely low birth weight infant. Pediatrics 1995;96(3 Pt 1):484-9.

25. Kavvadia V, Greenough A, Dimitriou G, Forsling ML. Randomized trial of two levels of fluid input in the perinatal period-effect on fluid balance, electrolyte and metabolic disturbances in ventilated VLBW infants. Acta Pediatr 2000;89:237-41.

26. Barrington KJ. Management during the first $72 \mathrm{~h}$ of age of the periviable infant: an evidence-based review. Semin Perinatol 2014;38:17-24.

27. Tammela OK, Koivisto ME. Fluid restriction for preventing bronchopulmonary dysplasia? Reduced fluid intake during the first weeks of life improves the outcome of low-birth-weight infants. Acta Pediatr 1992;81:207-12. 


\section{Articles | Späth et al.}

28. Costarino AT Jr, Gruskay JA, Corcoran L, Polin RA, Baumgart S. Sodium restriction versus daily maintenance replacement in very low birth weight premature neonates: a randomized, blind therapeutic trial. J Pediatr 1992;120:99-106.

29. Hartnoll G, Betremieux P, Modi N. Randomised controlled trial of postnatal sodium supplementation on oxygen dependency and body weight in 25-30 week gestational age infants. Arch Dis Child Fetal Neonatal Ed 2000;82:F19-23.
30. Koletzko B, Goulet O, Hunt J, Krohn K, Shamir R; Parenteral Nutrition Guidelines Working Group; European Society for Clinical Nutrition and Metabolism; European Society of Pediatric Gastroenterology, Hepatology and Nutrition (ESPGHAN); European Society of Pediatric Research (ESPR). 1. Guidelines on Pediatric Parenteral Nutrition of the European Society of Pediatric Gastroenterology, Hepatology and Nutrition (ESPGHAN) and the European Society for Clinical Nutrition and Metabolism (ESPEN), supported by the European Society of Pediatric Research (ESPR). J Pediatr Gastroenterol Nutr 2005;41 Suppl 2:S1-87. 